\title{
Assessment Of Breast Self- Examination And Associated Factors Among Women Age 20-64 Years At Arba Minch Zuria District, Gamo Zone Snnpr Ethiopia, 2019
}

\section{Birknesh Mereta}

Arba Minch Nursing college

Mulugeta Shegaze

Arba Minch University

\section{Bitew Mekonnen}

Arba Minch University

Nathan Desalegn

Arba Minch University

Asmare Getie ( $\square$ asmaregetie2017@gmail.com )

Arba Minch University https://orcid.org/0000-0002-4078-0078

Mustefa Glagn Abdilwohab

Arba Minch University

\section{Research}

Keywords: Arba Minch Zuria District, Breast Self-Examination, Practice

Posted Date: January 24th, 2020

DOI: https://doi.org/10.21203/rs.2.21847/v1

License: (c) (i) This work is licensed under a Creative Commons Attribution 4.0 International License.

Read Full License 


\section{Abstract}

Background Breast self-examination is simple, low cost and non-invasive method of noticing breast cancer by the women themselves for looking at and feeling for any change in their breast. Studies have shown that in Ethiopia the practice of breast self-examination is poor. So, the aim of this study is to address breast self-examination practice and associated factors among women aged 20-64 years at Arba Minch Zuria district, Gamo Zone southern Ethiopia.

Methods community-based cross-sectional study was conducted among 634 women aged 20-64 years at Arbaminch Zuria district using multi-stage sampling technique to select the study participants. Structured, pretested and interviewer-administered questionnaire was used to collect data. Data were entered in to EPI INFO version 3.5.1 and exported to SPSS version 22 for analysis. A binary logistic regression model was used to assess the association between independent and outcome variables. Adjusted odd ratio with $95 \%$ confidence interval and P-value of $<0.05$ was considered to declare a result as statistically significant.

Result A total of 634 study participants were involved, making a response rate of $100 \%$. From the total study participants only $21.3 \%$ had ever practice breast self-examination. There were a negative association between women age 40-49(AOR: $2.95 ; 95 \% \mathrm{Cl}: 1.23,7.06)$, and women who attended elementary level of education (AOR $0.33 ; 95 \% \mathrm{Cl} 0.14,0.60$ ). While women having good knowledge (AOR $0.58 ; 95 \% \mathrm{Cl} 0.30,0.92)$, and having good perceived benefit (AOR 2.22; $95 \% \mathrm{Cl} 1.85,34.1$ ) were the factors who were significantly positively associated with breast self-examination practice.

Conclusion Breast Self-Examination Practice among the study participants was low. Educational status, age, knowledge and perceived benefits towards breast -self-examination were associated with breast selfexamination practice. Therefore, much more Efforts should be taken by stakeholders in different hierarchies to promote women's education, promoting and advocating breast self-examination practice.

\section{Background}

Cancer is a group of diseases that cause cells in the body to change and spread out of control. It is a global public health problem, touching all area of the world and socioeconomic groups affecting $12 \%$ of all cancer death worldwide. Breast cancer is the second most common, frequently diagnosed cancer in the world and, by far, characterized by abnormal growth of cells lining the breast lobules or $\operatorname{duct}(1,2)$ Worldwide, there were about 2.1 million newly diagnosed female breast cancer cases in 2018, accounting for almost 1 in 4 cancer cases among women $(3,4)$. Breast cancer-related illness and death can be decreased by timely detection by means of screening programs, as it not only increases the probability for successful medication and cure of the disease but also improves chances of survival and lessens the need of invasive treatment (1)

The three screening methods currently recommended by the American Cancer Society are clinical breast examination (CBE), mammography, and breast self-examination (BSE). Breast self-examination (BSE) is 
one of the early detection methods used for early detection of breast cancer and females can check by themselves in private in their own by getting the know-how of the normal breast look and feel $(5,6)$. Breast cancer is a manageable disease, in case of early diagnosis with sufficient treatment protocols such as advanced surgical intervention, chemotherapy, and radiation therapies. But the main focus is early detection through screening(7)

Breast self-examination (BSE) is simple, very low cost, non-invasive early detection method used to detect breast cancer at early stage, which involves women who are 20 years old and above can practice by herself looking at and feeling for any change in their breast $(8,9)$. Breast self-examination practice remains low in many countries, a study conducted in Saudi Arabia showed that breast selfexamination was only $8.4 \%$ (10). Another study conducted in Ethiopia ,Adwa town showed that BSE was only $6.5 \%(11)$.

Breast cancer is the uppermost cancer in females both in the developed and the developing countries. The incidence of breast cancer is increasing in the developing countries due to increase life expectancy, increase urbanization and adoption of western lifestyles $(12,13)$.

According to Global cancer statistic, there were an estimated 2.1 million new cases of breast cancer and 630,000 deaths due to breast cancer in 2018(14).In the United States alone, there were an estimated 270,000 cases of breast cancer diagnosed in 2018 along with 41,000 deaths, and approximately 1 in 8 women(15). The disease is the leading cause of cancer death in over 100 countries(3).

In Ethiopia, breast cancer is the first leading cancer among females with $24.4 \%$ prevalence rate. In 2014, 12,956 women were diagnosed with breast cancer and 26,200 women died by breast cancer(17)(16). Despite the fact that Prevention is the best alternative to undertake the rising morbidity and mortality by breast cancer, some early detection methods such as mammography are inaccessible for women who live in developing countries like Ethiopia. In such area's mammography cannot be an option in routine practice since it is expensive and needs sophisticated technology trained professionals. Even Clinical Breast Examination is not much viable for them as it needs professional skills and regular health facility visit which is especially hard to women living in rural areas(17)

However Breast Self-Examination is said to be the least costly, less time consuming and noninvasive screening method, several studies shown in Ethiopia reported that the practice of breast self-examination is poor and the most frequently revealed reasons for not practicing this behavior were not knowing the technique of performing BSE, not having breast related problem or symptoms, fearful of being detected with breast cancer and no advice or recommendation from Health care workers (HCWs) (18-20). There is limited study conducted in Ethiopia on the breast self-examination. Moreover, there is no study done in Arba Minch zuria district that reveal Breast self-examination and its associated factors. So the aim of this study is to assess level of breast self-examination and its associated factors among women aged 20-64 years old in the study area. 


\section{Methods}

Study setting, design and population

Arbaminch zuria Districtis is found in Southern Nation Nationalities and People Region Gamo Zone, around Arbaminch Town located $505 \mathrm{~km}$ southwest from the capital city, Addis Ababa and 275km far from Hawassa city of SNNPR. Based on the 2007 census conducted by the Central statistical Agency of Ethiopia and population projection for 2017, the total population of Arbaminch zuria District is 195,858 ; of whom $50.01 \%$ are women(21).

Source population

All Women who are Age between 20-64 Years old

Study population

All Women who are Age between 20-64 Years old during the study period

\section{Study design}

A community based cross-sectional study design was conducted

\section{Sample size determination}

In this study, sample size was determined by using single population proportion formula by considering the level of breast self-examination $50 \%$, margin of error of $5 \%$, and confidence level $95 \%$, design effect 1.5 and adding non-response rate of $10 \%$. So, the sample size for this study was 634 .

\section{Sampling procedure}

A multi-stage sampling technique was employed to select the study participants. Arba Minch Zuria district has 29 kebeles (the smallest administrative unit in Ethiopia) from which nine kebeles were selected by lottery method. First, eligible households were identified from family folder belongs to health post in each kebeles. If there are two and more than two participants in the house one of them would be taken by lottery methods. Three visits were conducted during data collection in case when the data collectors didn't get the study participants. Then, eligible households were coded in to computer, finally, computer generated random numbers were used to select households with eligible study participants.

\section{Data Collection tools and techniques}


The tool was adapted from the champion's breast self-examination questionnaire and from different literature reviews $(53,54)$. The questionnaire was first prepared in English and, it was translated to Gamoegna language and back to English by language expert. The data were collected by nine data collectors and two supervisors using face-to-face interviewer administered pre-tested questionnaires.

\section{Data quality control}

The questionnaire was pre-tested on $5 \%$ (32) of the total sample size of non-study subjects in Mirab Abaya woreda Delibo Kebele before the actual data collection. Training was given for data collectors \& supervisors for 2 days by the investigators on the purpose of the study, method of interviewing; keeping confidentiality of information and other essential principles. The overall activities of data collection were supervised and coordinated by the investigators. The completeness of the questionnaire was checked by supervisor at the end of each day and double checked by investigators.

\section{Data processing and analysis}

Collected questionnaire were checked manually for its completeness, coded entered in to EPI INFO version 3.5.1and exported to SPSS version 22 for data cleaning and analysis. Each of the 3 breast selfexamination questions were summed and the result with mean and higher score denoting good practice. The Hosmer-Lemeshow test was used to check the goodness of fit of the model. Bivariate analysis was done to identify associations between dependent and independent variables, with crude and adjusted odd ratios, $95 \% \mathrm{Cl}$ and $\mathrm{p}$-values were used to assess the strength of associations and statistical significance. Variables with a p-value of $<0.25$ in bivariate analysis were considered as candidate for multivariable analysis; and variables with a p-value of $<0.05$ level in the multivariable analysis were considered as significant factors of breast self-examination practice in the final logistic regression analysis.

\section{Operational definition}

Breast self-examination practice: If the woman has performed breast self-examination monthly during menses (regular) or ever performed breast self -examination (irregular) we considered as practiced BSE.

Knowledge towards breast self- examination: -was assessed through 7 items on breast Self-examination. Respondents who score less than or equal to the mean value was considered as Poor knowledge (23).

Attitude towards breast self-examination: - was assessed through 3 questions and Respondents who scored above the mean value, was considered as having "favorable" attitude while those who scored below or equal to the mean value was considered as having "unfavorable" attitude towards breast selfexamination (23).

Perceived susceptibility towards breast self-examination: - participants who scored mean and above the mean values regarding their risk of breast cancer from the provided 3 close-ended questions were 
considered as having good perceived susceptibility (54).

Perceived severity towards breast self-examination: - participants who scored mean and above the mean values regarding their consequence of breast cancer from the provided 4 close-ended questions were considered as having good perceived seriousness (54).

Perceived benefits toward breast self examination: - participants who scored mean and above values regarding the benefit of BSE from the provided 4 close ended questions were considered as having good perceived benefits (53)

Perceived barriers towards breast self-examination: - participants whose answered to barrier related questions to do BSE measured by 3 questions, and scored mean above values was considered as having a perceived barrier to do BSE (53)

\section{Results}

\section{Socio demographic characteristics of Respondents}

From the total of 634 respondents, all of them had completed the questionnaire sufficiently making the response rate of $100 \%$. The age of the study participants ranged from 20 to 62 years with a mean age of $34.96 \pm 11.038$ SD. The mean monthly income was 1029.01 while $(52.4 \%)$ of the participants earn less than 500 ETB. Occupations of the respondents and the rest were also mentioned in the table (table 1).

\section{Knowledge and attitude of respondents towards breast self- examination practice}

From the overall participants, $34.2 \%$ of the respondents have knowledgeable on BSE. Broad castings were the predominant source of information which was, $53.1 \%$ of the total respondents followed by Health professionals, $29.7 \%$, and $17.1 \%$ were from families and friends. Among total respondents around $14.5 \%$ participants have positive attitude towards to BSE (table 2 ).

\section{Perception of respondents about breast self-examination practice}

From the total respondents, $21.3 \%$ where practiced BSE and having good perceived benefit which accounts $98.5 \%$. A good perceived benefit respondent (38.1\%) was between 20-29 age groups. Regarding perceived self-efficacy towards BSE in the study (82.8\%) had good perceived self-efficacy. All respondents who have good perceived self-efficacy were experienced breast self-examination (figure 1).

\section{Magnitude of Breast Self-Examination among respondents}


In this study the magnitudes of breast self-examination practice among respondents showed was (21.3\%).

\section{Frequency of BSE practice among respondents}

Out of those who performed BSE (13.3\%) were reported to practice monthly interval and the rest do not practice regularly (figure 2 ).

\section{Respondents reason for BSE practice}

From the total respondents less than one fourth (21.3\%) were practice BSE, and the main reason of performing BSE (75.4\%)) were for early detection and treatment, $(8.3 \%)$ had breast problem, $(13.4 \%)$ fear of breast cancer, and the rest (3.0\%) were Fear of developing breast cancer from family.

\section{Reasons of respondents for not practicing breast self-examination}

From the total respondents nearly three-fourth (78.7\%) of them did not practice BSE. The main reasons for not practicing BSE identified in the present study were (50.7\%) not knowing how to perform it, $(20.4 \%)$ not having breast problem, $(16.4 \%)$ not having breast symptom, and (12.4\%) lack of knowledge about its importance.

\section{Factors associated with breast self-examination practice}

\section{Discussion}

This study aimed to assess the practice of breasts self -examination and associated factors among women aged 20-64 at Arba Minch zuria district, southern Ethiopia. It was found that the magnitude of BSE was $21.3 \%$.This finding was consistent with the study conducted in Debre Birhan which was (28.3\% )(22). The finding of this study was lower than the study conducted at Mekele, Wolayita zone, and Nigeria which was $53.6 \%, 45.6 \%$ and $43.5 \%$ respectively $(23,24)(25)$. This may be due to different Socio demographic factors like low level of educational and economic status in the district. On the other hand the finding of this study was higher than studies conducted at Ondo state and Aduwa town which was $13 \%$ and $6.5 \%$ respectively $(11,26)$. This difference might be due to sample size difference, participant's knowledge towards BSE practice, and socio economic and cultural variation.

The finding of this study revealed that $34.2 \%$ of participants were knowledgeable on BSE practice. This finding is consistent with the study conducted at Debre Birhan and Malaysia which was $35 \%$ and $38.4 \%$ respectively $(22,27)$. This finding is also lower than a study conducted at Buea Cameroon which was $59.17 \%(28)$. This might be due to sampling procedure, and socio demographic characteristics of participants in the previous study. 
In this study women age was one of the significant factors for the breast self-examination practice, women practice, women whose age 40-49 years were nearly three times more likely to practice BSE than those women whose age greater than 50 with (AOR: 2.95; 95\% Cl: 1.23, 7.06). Study conducted in rural areas of south India, the practice was highest among those aged 51-60 years which was $(37.21 \%)$ and it was lowest for those aged less than 30 years $(11.54 \%)$ which was found to be statistically significant $(P=0.004)(29)$.The current study indicates that age increases performance of BSE decrease.

In this study women's educational level was one of the significant factors for the practice of breast selfexamination, Women who attended elementary level of education were $67 \%$ with less likely to practice breast self-examination as compared with those college and above level of education with ((AOR: 0.33; $95 \% \mathrm{Cl}: 0.17,0.62)$.This finding was supported by the Study done in Nigeria ,south India, and Mekele (29) (28). This indicates that as the educational status of the women get improved; breast self-examination behavior of the women's possibly increases.

The finding of this study showed that knowledge of women was significant factor for BSE practice, Those Women knowledgeable on BSE were $58 \%$ times (AOR $0.42,95 \% \mathrm{Cl}: 0.27,0.65$ ) more likely to examine their breast than those who were not knowledgeable. This study was in line with the study conducted in Addis Ababa, (30). This indicates that women who were knowledgeable on BSE were more likely to practice than those who were not knowledgeable.

This study revealed that significant association was observed between perceived benefit and the practice of breast self- examination, the odd of women with good perceived benefit had nearly two times more likely to practice breast self-examination as compared with the counterparts with (AOR: $2.22 ; 95 \% \mathrm{Cl}: 1.18$, 4.19). This finding was supported by a study done in western Turkey(31).

\section{Conclusion}

Despites the importance of breast self-examination, the practice of breast self-examination was significantly low. This study revealed that educational status being at elementary level, age 40-49 years, having good knowledge, and good perceived benefit were found to be significantly associated with BSE practice. Arba Minch Zuria district Health office should stress on educating women's regarding to Breast Self-Examination. All stake holders: civil society, NGO, and government agencies should work jointly to develop community awareness and to improve women educational status.

\section{Abbreviations}

BSE: Breast Self-Examination

CBE: Clinical Breast Examination

HCWs: Health Care Workers 


\section{Declarations}

\section{Ethical Statement}

Ethical approval was obtained from Institutional Ethics Review Board (IRB) of Arba Minch University. In addition, an official letter was issued from the College of Health and Medical Sciences, Arba Minch University to Arba Minch Zuria District. After securing permission from the district, the actual data collection was commenced after obtaining written and signed voluntary consent from each study participant. All information collected from the participants was kept confidential.

\section{Acknowledgements}

The authors are grateful for the data collectors, study participants and supervisors for their collaboration during the entire research activity.

\section{Availability of data and material}

The datasets used and/or analyzed during the current study available from the corresponding author on reasonable request.

\section{Consent for publication}

Not applicable

\section{Funding}

Not applicable

\section{Competing interests}

The authors declare that they have no competing interests.

\section{Author's contribution}

B M designed the study, drafted the paper, involved in the data collection, do analysis and interpretation of the results and participated in preparing all versions of the manuscript. MS, BM, ND, MG and AG assisted in the design and in the proposal development, monitored data collection, assisted during analysis and revised subsequent drafts of the paper. All authors read and approved the final manuscript. 


\section{References}

1. Lee S, Kim YH, Kim SC, Joo JK, Seo DS, Kim KH, et al. The effect of tamoxifen therapy on the endometrium and ovarian cyst formation in patients with breast cancer. Obstetrics \& gynecology science. 2018;61(5):615-20.

2. Smith RA, Manassaram-Baptiste D, Brooks D, Doroshenk M, Fedewa S, Saslow D, et al. Cancer screening in the United States, 2015: a review of current American cancer society guidelines and current issues in cancer screening. CA: a cancer journal for clinicians. 2015;65(1):30-54.

3. GLOBOCAN Cancer estimates of Incidence and Mortality worldwide for 36 cancers in 185 countris. Ca cancer J CLIN 2019. 2018;68(394-42).

4. Alanzi TM, Alobrah A, Alhumaidi R, Aloraifi S. Evaluation of the SnapChat mobile social networking application for breast cancer awareness among Saudi students in the Dammam Region of the Kingdom of Saudi Arabia. Breast Cancer: Targets and Therapy. 2018;10:113.

5. Majeda M KA, Samia S, et al. knowledge and factors affecting breast self-examination among kuwaiti women. . kuwaiti medical J. 2008;40(1):103-10.

6. Al Qattan MM, Al Saleh KA, Al Musallam SS, Mosoud GM. Knowledge and factors affecting breast self-examination among Kuwaiti women. KMJ-Kuwait Medical Journal. 2008:103-10.

7. Misganaw A, Mariam DH, Ali A, Araya T. Epidemiology of major non-communicable diseases in Ethiopia: a systematic review. Journal of health, population, and nutrition. 2014;32(1):1.

8. Smith RA, Cokkinides V, Brawley OW. Cancer screening in the United States, 2008: a review of current American Cancer Society guidelines and cancer screening issues. CA: A Cancer Journal for Clinicians. 2008;58(3):161-79.

9. Smith RA, Andrews KS, Brooks D, Fedewa SA, Manassaram-Baptiste D, Saslow D, et al. Cancer screening in the United States, 2017: a review of current American Cancer Society guidelines and 
current issues in cancer screening. CA: a cancer journal for clinicians. 2017;67(2):100-21.

10. Sharaa HM. Beliefs and reported practices related to breast self-examination among sample of Egyptian women. Academic Journal of Cancer Research. 2013;6(2):99-110.

11. Abay M, Tuke G, Zewdie E, Abraha TH, Grum T, Brhane E. Breast self-examination practice and associated factors among women aged 20-70 years attending public health institutions of Adwa town, North Ethiopia. BMC research notes. 2018;11(1):622.

12. WHO. world health organization. Breast Cancer: Prevention and control: . 2014[cited 2019 February 1].

13. Colditz GA, Bohlke K. Priorities for the primary prevention of breast cancer. CA: a cancer journal for clinicians. 2014;64(3):186-94.

14.Bray F, Ferlay J, Soerjomataram I, Siegel RL, Torre LA, Jemal A. Global cancer statistics 2018 : GLOBOCAN estimates of incidence and mortality worldwide for 36 cancers in 185 countries. CA: a cancer journal for clinicians. 2018;68(6):394-424.

15. George M, Denton E, Zwiggelaar R, editors. Mammogram breast density classification using meanelliptical local binary patterns. 14th International Workshop on Breast Imaging (IWBI 2018); 2018: International Society for Optics and Photonics.

16. Ginsburg O, Bray F, Coleman MP, Vanderpuye V, Eniu A, Kotha SR, et al. The global burden of women's cancers: a grand challenge in global health. The Lancet. 2017;389(10071):847-60.

17. Akhtari-Zavare M, Ghanbari-Baghestan A, Latiff LA, Matinnia N, Hoseini M. Knowledge of breast cancer and breast self-examination practice among Iranian women in Hamedan, Iran. Asian Pacific Journal of Cancer Prevention. 2014;15(16):6531-4. 
18. Birhane K AM, Anawte B, Gebremariyam G, Daniel R, Addis S, et al. Practices of Breast SelfExamination and Associated Factors among Female Debre Berhan University Students. International journal of breast cancer. 2017.

19. Birhane N MA, Girma E, Asfaw S. Predictors of breast self-examination among female teachers in Ethiopia using health belief model. 2015.

20. Teferi S MT, Demissie M, Durgaprasada A. Knowledge about breast cancer risk-factors, breast screening method and practice of breast screening among female healthcare professionals working in governmental hospitals, Addis Ababa, Ethiopia. IOSR Journal of pharmacy and biological sciences. 2012;2(1):5-12.

21. CSA C. Federal Democratic Republic of Ethiopia population projection of Ethiopia for all regions at wereda level from 2014-2017,(August 2013). Ethiopia: Addis Ababa. 2014.

22. Birhane K, Alemayehu M, Anawte B, Gebremariyam G, Daniel R, Addis S, et al. Practices of breast selfexamination and associated factors among female debre berhan university students. International journal of breast cancer. 2017;2017.

23. Legesse B, Gedif T. Knowledge on breast cancer and its prevention among women household heads in Northern Ethiopia. Open Journal of Preventive Medicine. 2014;4(01):32.

24. Hamad KJ, Khalil HM, Awlla HA. KNOWLEDGE OF BREAST CANCER RISK FACTORS AND PRACTICE OF BREAST SELF EXAMINATION AMONG FEMALE STUDENTS OF SORAN TECHNICAL INSTITUTE. Polytechnic Journal. 2018;8(3):203-18.

25. Neji O, Kalu U, Bamidele E. Breast cancer awareness and practice of breast self examination among women in Adiabo community in Odukpani local government area of Cross River State, Nigeria. Clinical Nursing Studies. 2016;4(1):50-6. 
26. Makanjuola O, Amoo P, Ajibade B, Makinde O. Breast cancer: knowledge and practice of breast self examination among women in rural community of Ondo State, Nigeria. IOSR J Pharm Biol Sci. 2013;8(1):32-7.

27. Akhtari-Zavare M, Juni MH, Ismail IZ, Said SM, Latiff LA. Barriers to breast self examination practice among Malaysian female students: a cross sectional study. SpringerPlus. 2015;4(1):692.

28. Suh MAB, Atashili J, Fuh EA, Eta VA. Breast self-examination and breast cancer awareness in women in developing countries: a survey of women in Buea, Cameroon. BMC research notes. 2012;5(1):627.

29. Yerpude PN, Jogdand KS. Knowledge and practice of breast self-examination (BSE) among females in a rural area of South India. Natl J Community Med. 2013;4(2):329-32.

30. Getu MA, Kassaw MW, Tlaye KG, Gebrekiristos AF. Assessment of breast self-examination practice and its associated factors among female undergraduate students in Addis Ababa University, Addis Ababa, Ethiopia, 2016. Breast Cancer: Targets and Therapy. 2019;11:21.

31. Dündar PE, Özmen D, Öztürk B, Haspolat G, Akyıldız F, Çoban S, et al. The knowledge and attitudes of breast self-examination and mammography in a group of women in a rural area in western Turkey. BMC cancer. 2006;6(1):43.

\section{Tables}




\begin{tabular}{|c|c|c|c|}
\hline Variables & Category & Frequency & Percent \\
\hline \multirow[t]{4}{*}{ Age in year } & $20-29$ & 230 & 36.3 \\
\hline & $30-39$ & 200 & 31.5 \\
\hline & $40-49$ & 117 & 18.5 \\
\hline & $=>50$ & 87 & 13.7 \\
\hline \multirow[t]{4}{*}{ Marital status } & Single & 72 & 11.4 \\
\hline & Married & 528 & 83.3 \\
\hline & Divorced & 12 & 1.9 \\
\hline & Widowed & 22 & 3.5 \\
\hline \multirow[t]{3}{*}{ Religion } & Protestant & 403 & 63.6 \\
\hline & Orthodox & 201 & 31.7 \\
\hline & Others & 30 & 4.7 \\
\hline \multirow[t]{6}{*}{ Occupation } & House wife & 459 & 72.4 \\
\hline & Government employee & 35 & 5.5 \\
\hline & Private employee & 39 & 6.2 \\
\hline & Merchant & 52 & 8.2 \\
\hline & Daily laborer & 19 & 3.0 \\
\hline & Student & 30 & 4.7 \\
\hline \multirow[t]{4}{*}{ Educational status } & Read and write & 301 & 47.5 \\
\hline & Elementary & 139 & 21.9 \\
\hline & High school & 103 & 16.2 \\
\hline & College or university & 85 & 14.4 \\
\hline \multirow[t]{3}{*}{ Monthly income } & $<500$ & 332 & 52.4 \\
\hline & $500 ; 1000$ & 194 & 30.9 \\
\hline & $>1001$ & 106 & 16.7 \\
\hline \multirow[t]{2}{*}{ Previous history of breast problem } & Yes & 58 & 9.1 \\
\hline & No & 576 & 90.9 \\
\hline \multirow[t]{2}{*}{ Family history of breast cancer } & Yes & 16 & 2.5 \\
\hline & No & 618 & 97.5 \\
\hline
\end{tabular}




\begin{tabular}{|c|c|c|c|}
\hline Knowledge related questions & & frequency & Percent \\
\hline \multirow{2}{*}{ 1. Did you hear about breast cancer } & yes & 501 & 79.0 \\
\hline & no & 133 & 21.0 \\
\hline \multirow{2}{*}{ 1. Did you hear about breast self -examination } & yes & 350 & 55.2 \\
\hline & NO & 284 & 44.8 \\
\hline \multirow{2}{*}{ 1. BSE helps to observe for unusual change } & yes & 284 & 44.8 \\
\hline & no & 350 & 55.2 \\
\hline \multirow{2}{*}{ 1. Breast self-examination should be done monthly } & yes & 80 & 12.6 \\
\hline & no & 554 & 87.4 \\
\hline \multirow{2}{*}{ 1. Hands should be raised up alternately above the head } & yes & 182 & 28.7 \\
\hline & no & 452 & 71.3 \\
\hline \multirow{2}{*}{ 1. BSE should be done by standing in front of mirror } & yes & 168 & 26.5 \\
\hline & no & 466 & 73.5 \\
\hline \multirow{2}{*}{ 1. BSE should be done by Lying down/supine } & yes & 284 & 44.8 \\
\hline & no & 350 & 55.2 \\
\hline
\end{tabular}




\begin{tabular}{|c|c|c|c|c|c|c|}
\hline \multirow[t]{3}{*}{ Variables } & & \multicolumn{2}{|c|}{ BSE practice } & \multirow{3}{*}{$\begin{array}{c}\text { Crude OR (95\%) } \\
\text { CI }\end{array}$} & \multirow{3}{*}{$\begin{array}{l}\text { Adjusted } \\
\text { OR (95\%) CI }\end{array}$} & \multirow[t]{3}{*}{ P-value } \\
\hline & & & & & & \\
\hline & & YES & NO & & & \\
\hline \multirow[t]{4}{*}{ Age } & $20-29$ & 52 & 178 & $2.88(1.30,6.35)$ & $1.79(0.78,4.10)$ & 0.17 \\
\hline & $30-39$ & 46 & 154 & $2.95(1.32,6.55)$ & $2.01(0.85,4.78)$ & 0.51 \\
\hline & $40-49$ & 29 & 88 & $3.25(1.40,7.53)$ & $2.95(1.23,7.06) * *$ & 0.01 \\
\hline & $>=50$ & 8 & 79 & 1 & 1 & \\
\hline Educational & Read and write & 54 & 247 & $0.34(0.31,0.57)$ & $0.58(0.32,1.00)$ & 0.05 \\
\hline \multicolumn{7}{|l|}{ Status } \\
\hline & elementary & 25 & 210 & $0.78(0.44,1.37)$ & $0.33(0.17,0.62) * *$ & 0.001 \\
\hline & High school & 22 & 81 & $0.43(0.23,0.81)$ & $0.54(0.28,1.04)$ & 0.07 \\
\hline & College or university & 35 & 56 & 1 & 1 & \\
\hline \multirow[t]{2}{*}{ Perceived benefit } & Good & 122 & 376 & $0.069(0.20,0.57)$ & $2.22(1.18,4.19) * *$ & 0.01 \\
\hline & Poor & 213 & 123 & 1 & 1 & \\
\hline Perceived barrier & Good & 6 & 64 & $0.32(0.13,0.75)$ & & \\
\hline \multirow[t]{3}{*}{ Knowledge } & Poor & & & 1 & & \\
\hline & Good & 76 & 141 & $0.31(0.21,0.45)$ & $0.42(0.27,0.65) * *$ & 0.00 \\
\hline & poor & 59 & 385 & 1 & 1 & \\
\hline
\end{tabular}

\section{Table Legends}

Table 1 Socio Demographic Characteristics of Respondents for BSE among Arba Minch Zuria District, South Ethiopia, 2019

Table 2 Respondents knowledge on breast self-examination practice among Arba Minch Zuria District, South Ethiopia, 2019

Table 3 Factors independently associated with Breast self-examination practice among Arba Minch Zuria district, South Ethiopia, May, 2019 
Figures

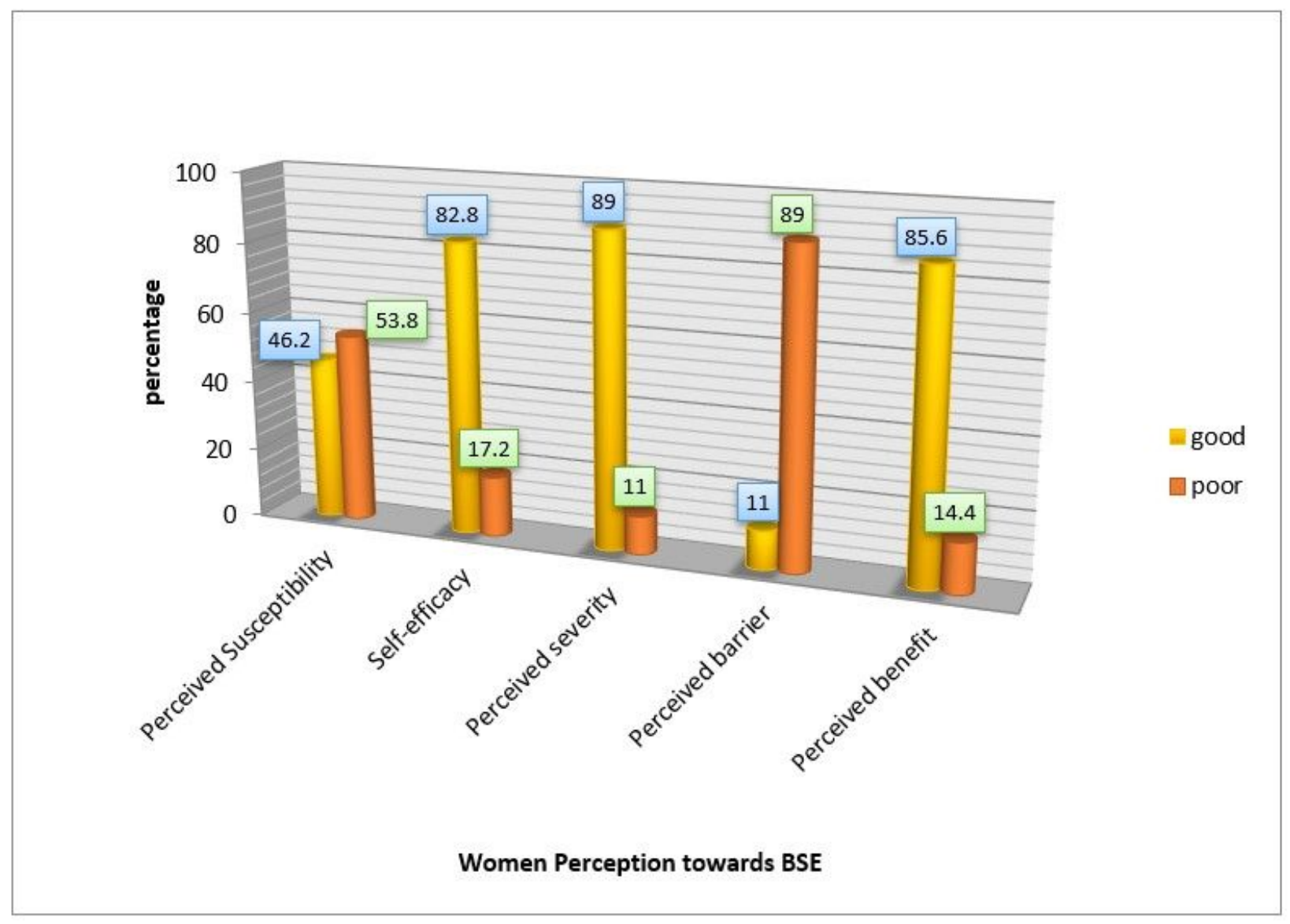

Figure 1

Distribution of Respondents Perception towards breast self-examination among women at Arba Minch Zuria District, South Ethiopia, 2019 


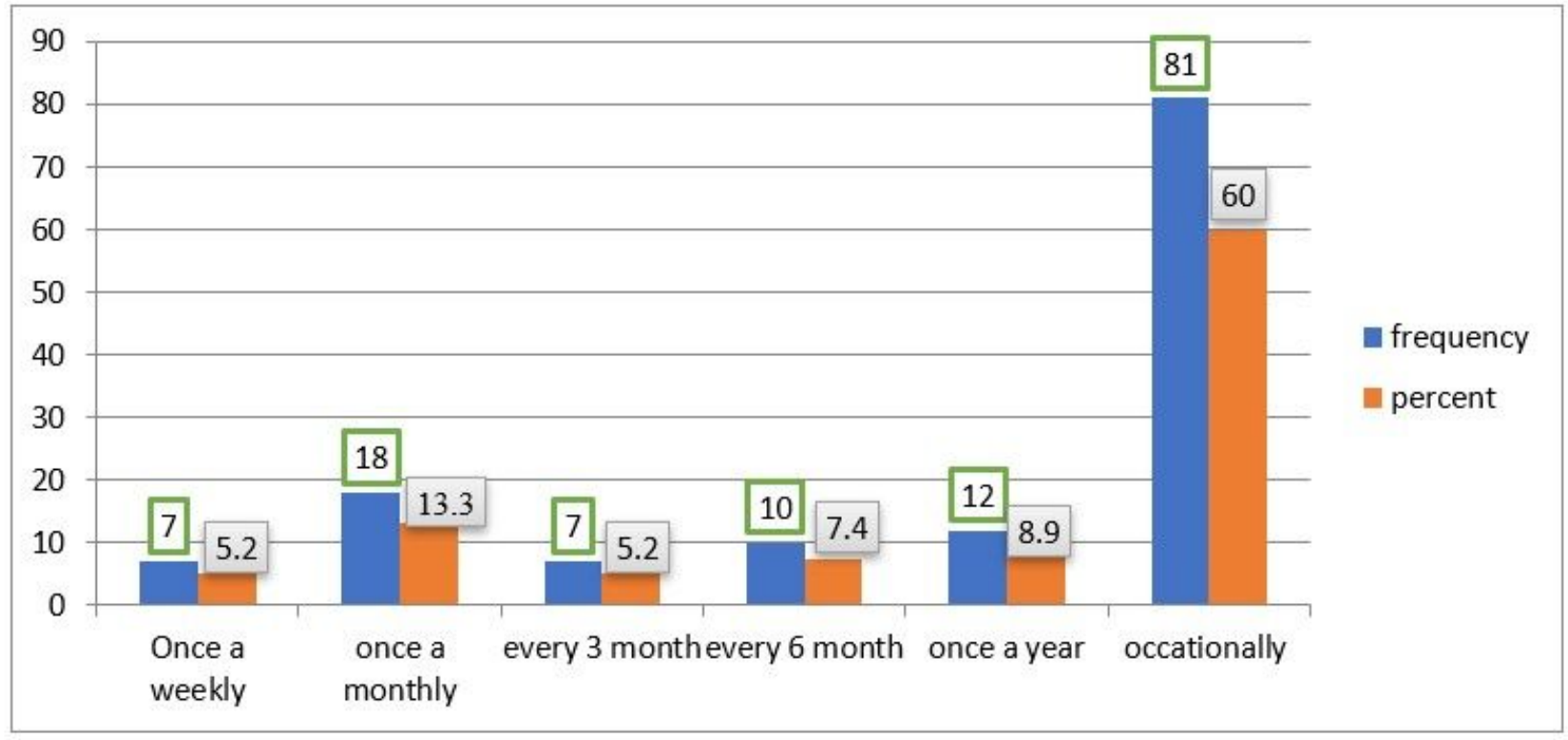

\section{Figure 2}

frequency of BSE practice among women at Arba Minch Zuria District, South Ethiopia, 2019 